\title{
Epigenetic alterations in hematopoietic malignancies
}

\author{
Young Rock Chung • Emma Schatoff • \\ Omar Abdel-Wahab
}

Received: 6 September 2012/Revised: 10 September 2012/ Accepted: 12 September 2012

(c) The Japanese Society of Hematology 2012

\begin{abstract}
Gene discovery efforts in patients with hematopoietic malignancies have brought to the forefront a series of mutations in genes thought to be involved in the epigenetic regulation of gene transcription. These mutations occur in genes known, or suspected, to play a role in modifying cytosine nucleotides on DNA and/or altering the state of histone modifications. Genes such as ASXL1, DNMT3A, EZH2, IDH1/2, MLL1, and TET2 all have been shown to be mutated and/or translocated in patients with myeloid malignancies. Intriguingly, many of the alterations affecting DNA cytosine modifications in myeloid malignancies (mutations in DNMT3A, IDH1/2, and TET2) have also been found in patients with T-cell lymphomas, and EZH2 mutations appear to be critical in T-cell acute lymphoblastic leukemia development as well. In addition, the discovery of frequent mutations in CREBBP, EP300, $E Z H 2$, and MLL2 in B-cell lymphomas suggests that epigenetic alterations play a critical role in lymphomagenesis. The purpose of this review is to present functional evidence of how alterations in these epigenetic modifiers promote hematopoietic transformation. The conclusions drawn from these data are valuable in understanding biological mechanisms and potential therapeutic targets.
\end{abstract}

Keywords ASXL1 - BAP1 - Chromatin - CREBBP . DNMT3A - Epigenetics - EP300 - EZH2 - IDH1 - IDH2 ·

Y. R. Chung · E. Schatoff · O. Abdel-Wahab $(\bowtie)$ Human Oncology and Pathogenesis Program and Leukemia Service, Memorial Sloan-Kettering Cancer Center, 1275 York Avenue, New York, NY 10065, USA

e-mail: abdelwao@mskcc.org
Leukemia $\cdot$ Lymphoma - Methylation · MLL . Myelodysplastic syndrome - TET2

\section{Introduction}

Epigenomic profiling studies have revealed alterations in DNA cytosine methylation $[1,2]$ and oxidized derivatives of methylated cytosines [3], as well as alterations in histone lysine methylation [4, 5], phosphorylation [6], and acetylation $[7,8]$ in patients with hematological malignancies. In parallel, genome discovery efforts in patients with hematopoietic malignancies have uncovered; in a short amount of time, a variety of somatic mutations in genes known to regulate DNA cytosine modifications as well as histone post-translational modifications. While clinical correlative studies have already identified the importance of many of these mutations for use in risk stratification of patients with myeloid leukemias $[9,10]$, the functional importance of aberrant chromatin modification and contribution of these mutations to hematopoietic transformation is not yet fully clear. Moreover, the therapeutic implications of the discovery of many of these alterations are not completely understood.

In this review, we discuss novel classes of mutated disease alleles in genes encoding epigenetic modifying proteins. These include somatic point mutations and/or translocations in ASXL1, CREBBP, DNMT3A, EP300, EZH2, IDH1/2, MLL1, MLL2, and TET2. This review focuses on epigenetic aberrations thought to be attributable to these mutations, and how these epigenetic alterations might contribute to hematopoietic transformation. In addition, we highlight the potential clinical value of understanding these mutations, as they may be therapeutically targetable in some instances. 


\section{Mutations affecting histone post-translational modifications}

Polycomb group alterations in hematopoietic malignancies

The Polycomb repressive complex 2 (PRC2), a complex originally identified in Drosophila, is an evolutionarily conserved complex, which serves the critical function of initiating and maintaining transcriptional silencing through specific post-translational modifications (PTM) of specific histones $[11,12]$. The PRC2 consists of four core members: EED, SUZ12, RbAp48, and EZH1 or enhancer of zeste homolog 2 (EZH2) [12]. EZH2 is a member of the Polycomb group (PcG) of proteins which has a highly conserved enzymatic activity of transferring methyl groups to histone H3 lysine 27 (H3K27) [13-16]. EZH2 has been implicated in transformation towards many human malignancies $[17,18]$, however, only in the past few years has it been identified as mutated in hematopoietic malignancies.

Somatic mutations in $E Z H 2$ were initially identified in lymphomas by Morin et al. [5] using exome sequencing. In lymphoid malignancies, recurring heterozygous somatic missense mutations in the SET domain of EZH2 has since been described at tyrosine 641 (Y641F, Y641N, Y641S and Y641H) [5], alanine 677 (A677G) [19], and at alanine 687 (A687V) [20]. These mutations in EZH2 are present in follicular lymphoma (FL) and germinal-center B-cell-like subtype (GCB) of diffuse large B-cell lymphomas (DLBCL). Initially, Morin and colleagues [5] showed that the $\mathrm{Y} 641 \mathrm{~F} / \mathrm{N}$ mutations result in a diminished ability of $\mathrm{EZH} 2$ to methylate histone $\mathrm{H} 3$ in an in vitro assay using recombinant unmethylated histone $\mathrm{H} 3$. At the same time, paradoxically, lymphoma cell lines with a Y641 EZH2 mutation appeared to have elevated H3K27me3 levels compared with wild-type cell lines. Later, Sneering et al. [21] and Yap et al. [22] revealed that the Y641 mutation, while impairing the ability of EZH2 to place an initial H3K27 methylation, results in an increased enzymatic activity to methylate mono- and dimethylated H3K27. This finding, in combination with the fact that the Y641 mutation is consistently heterozygous, suggests that the mutant $\mathrm{EZH} 2$ works in concert with wild-type EZH2 to result in increased $\mathrm{H} 3 \mathrm{~K} 27 \mathrm{me} 3$ and actually represents a gain-offunction mutation. Indeed, both studies revealed that PRC2 complexes containing mutant EZH2 preferentially catalyze di- and trimethylation of histone H3K27 with impaired ability to catalyze the initial H3K27 methyl mark on an unmodified histone H3 [21, 22]. More precisely, the catalytic efficiency $(\mathrm{kcat} / \mathrm{K})$ of the Y641 mutant EZH2 increases with the $\mathrm{H} 3 \mathrm{~K} 27$ methylation status. At the same time, the enzyme turnover number (kcat) of the Y641 mutant also increases with the substrate methylation status at $\mathrm{H} 3 \mathrm{~K} 27$. This is in distinct contrast with the enzymatic kinetics of the wild-type EZH2 protein, which shows greatest enzymatic activity when presented with an unmodified histone $\mathrm{H} 3$ and decreasing catalytic efficiency as H3K27 methylation increases. The EZH2 A687V mutation results in similar kinetics as the Y641F mutation, while the EZH2 A677G mutation enhances EZH2 enzymatic methylation regardless of $\mathrm{H} 3 \mathrm{~K} 27$ methylation state $[19,20]$.

Despite the strong in vitro enzymatic evidence that these EZH2 mutations confer gain-of-function activity resulting in increased $\mathrm{H} 3 \mathrm{~K} 27 \mathrm{me} 3$, identification of (1) the targets of the alterations in $\mathrm{H} 3 \mathrm{~K} 27 \mathrm{me} 3$ associated with these $E Z H 2$ mutations in lymphoma, and (2) the biological consequence of this altered enzymatic function remain unknown. Moreover, the discovery of gain-of-function recurrent mutations in $E Z H 2$ has led to the question of whether the differential enzymatic kinetics of the wild type and mutant forms of EZH2 can be harnessed for targeted therapy.

At the 2011 meeting of the American Society of Hematology (ASH), Berg et al. [23] described potential biological implications of gain-of-function mutations in $E Z H 2$. The authors created a transgenic mouse model of Ezh2 Y641F under controlled expression from the lymphoid specific E $\mu$-Lck promoter. Although mice with transgenic expression of Ezh2 Y641F in this manner were not found to develop any lymphoid or other malignancies, double-transgenic mice with overexpression of both Myc and Ezh2 Y641F revealed clear collaborative effects of the Ezh2 Y641F mutation. Mice expressing both Myc and Ezh2 Y641F developed a mature B-cell lymphoma, lymphadenopathy, and lymphocytosis at a faster rate than mice expressing Myc or Ezh2 Y641F alone. Further work to determine the targets of Ezh2 Y641F in vivo and to utilize this model for development of Ezh2 directed-therapies will hopefully be of great benefit.

In addition to the above-mentioned heterozygous missense mutations in the SET domain of EZH2 in lymphomas, a spectrum of somatic missense, nonsense, and frameshift mutations have been found throughout the open reading frame of EZH2 in myeloid malignancies [24] and in T-cell acute lymphoblastic leukemia (T-ALL) [25-27]. T-ALL is mainly driven by oncogenic activation of NOTCH1, and interestingly NOTCH1 activation appears to oppose PRC2-mediated gene silencing in the pathogenesis of T-ALL [25]. Indeed it has been shown that EZH2 and other PRC2 members are displaced from the promoters of a number of very well-established NOTCH1 target genes, such as HES1. Moreover, loss of EZH2 appears to result in increased tumorigenic potential of T-ALL xenografted cell lines.

In contrast to T-ALL, the enzymatic, epigenetic, and biologic consequences of loss-of-function, $\mathrm{EZH} 2$ mutations 
in myeloid malignancies remain to be elucidated. Moreover, why B-cell lymphoid malignancies harbor gain-offunction $E Z H 2$ mutations while myeloid malignancies and T-ALL harbor loss-of-function mutations remains to be explained. Curiously, mutations in EZH2 appear to be most common in myeloid malignancy patients with myelodysplastic syndrome (MDS) [10], myelofibrosis [28, 29], and MDS/myeloproliferative neoplasm (MPN) overlap syndromes [29], yet rare in patients with de novo acute myeloid leukemia (AML) [9]. Moreover, mutations in EZH2 appear to be one of the most robust biomarkers of adverse outcome in patients with de novo MDS. In two recent large comprehensive sequencing studies of patients deemed to have low-risk MDS based on clinical parameters by Bejar et al. [10, 30], EZH2 mutations were found to be the sole predictors of adverse outcome independent of the International Prognostic Scoring System or the MD Anderson Lower-Risk Prognostic Scoring System. Similarly, EZH2 mutations appear to be associated with adverse outcome in patients with primary myelofibrosis [28].

The discovery of mutations in EZH2 with opposite sequelae on its enzymatic activity in different types of hematopoietic malignancies suggests that EZH2 might function as both a tumor suppressor and oncogene (Fig. 1). Indeed, the earliest data linking EZH2 to malignancy came from studies of epithelial malignancies where ectopic overexpression of $\mathrm{EZH} 2$ in prostate epithelial cells was demonstrated to result in malignant transformation while RNAi-mediated knockdown of EZH2 inhibits proliferation of multiple malignant cell types [31, 32]. These results indicate that EZH2 has oncogenic capabilities when it is overexpressed [33]. However, in the hematopoetic compartment, inactivating mutations in EZH2 appear to be associated with malignant myeloid disorders as well as T-ALL. These findings suggest that EZH2 may also have a tumor suppressor function [33].

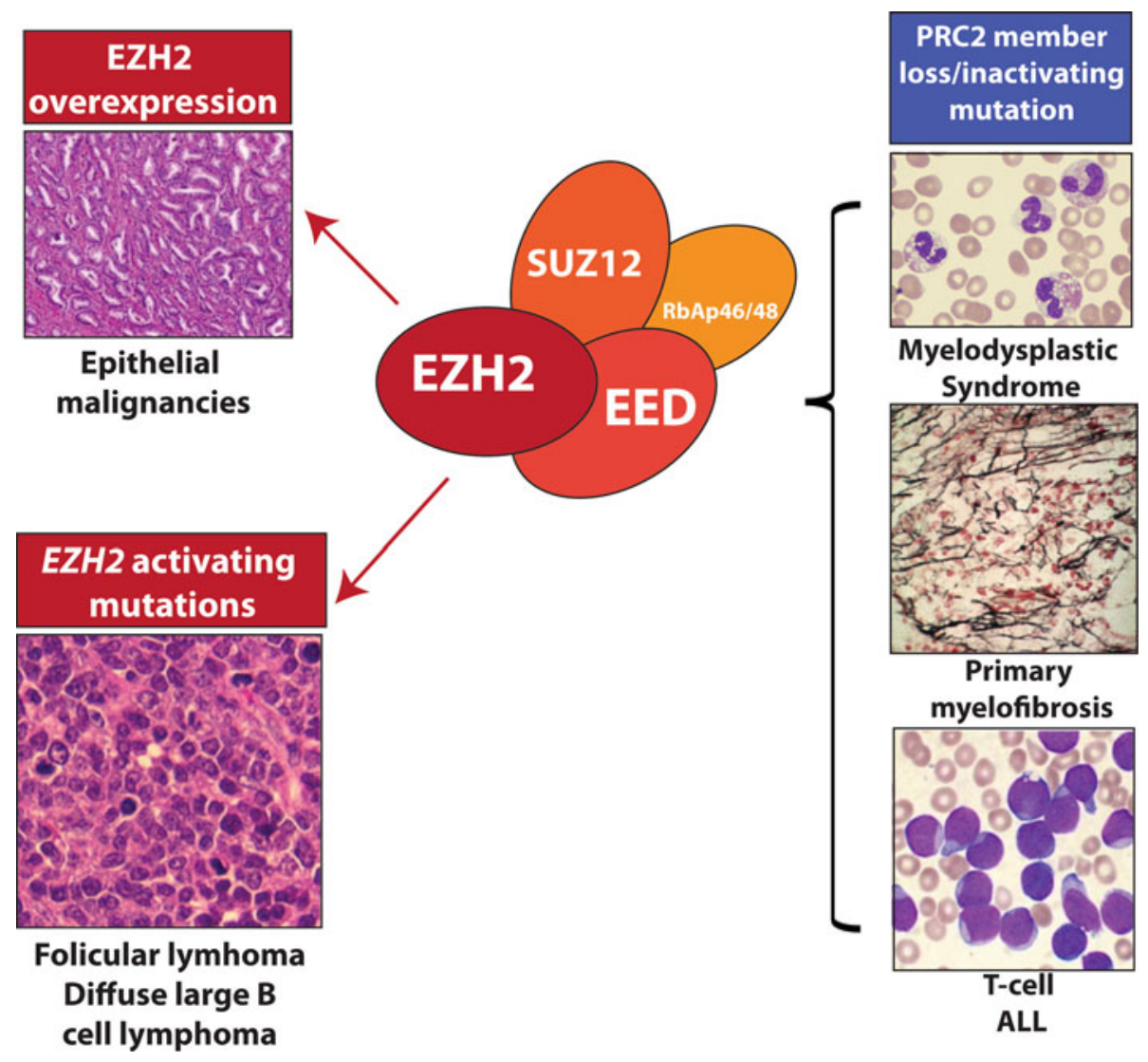

Fig. 1 EZH2 and the Polycomb repressive complex 2 (PRC2) appears to act as both an oncogene and tumor suppressor in patients with hematopoietic malignancies. Overexpression of EZH2, the catalytic member of the PRC2, has been clearly documented in the pathogenesis of a number of epithelial malignancies including prostate, breast, and bladder carcinomas (amongst others). In addition, a series of activating mutations in the SET domain of EZH2 have been discovered (EZH2 Y641, A677G, and A687V) in patients with follicular lymphoma and diffuse large B-cell lymphomas. In some cases, these mutant forms of EZH2 appear to collaborate with the wild-type form of EZH2 to result in hyperactivation of the histone $\mathrm{H} 3$ lysine 27 trimethylation activity of EZH2. More recently, however, somatic loss-of-function mutations and copy-number loss have been identified in $E Z H 2$ as well as other core PRC2 members in patients with myeloid malignancies and T-cell acute lymphoblastic leukemia. Curiously, among myeloid malignancy patients, EZH2 mutations appear to predominate in patients with myelofibrosis or some component of myelodysplasia 
The use of animal models to study the biological ramifications of perturbed Ezh2 expression has been somewhat enlightening for our understandanding of the seemingly dual functions of $E Z H 2$. Simon et al. [26] recently showed that conditional homozygous deletion of Ezh2 using inducible pan-hematopoietic deletion with Mx1 Cre resulted in the development of T-ALL in mice with a latency of at least 100 days following polyinosinic-polycytidylic acid (PIPC) administration. Mice with heterozygous deletion of Ezh2 did not appear to develop an overt malignancy. In contrast, Herrera-Merchan et al. [34] recently developed mice with conditional transgenic overexpression of Ezh2 through knockin of a floxed wild-type copy of Ezh2 into the ROSA26 locus. Overexpression of Ezh2 using panhematopoietic vav-Cre or tamoxifen inducible Cre-ER resulted in a very mild myeloproliferation and expansion of the hematopoietic stem cell compartment which amplified upon serial non-competitive transplantation.

In addition to the loss-of-function mutations in $\mathrm{EZH} 2$ described above, loss-of-function mutations in the other core members of the PRC2 complex have also been described in the same disorders as EZH2 mutations, namely in myeloid malignancies [35, 36] and T-ALL [25, 27]. In fact, mutations in any core member of the PRC2 complex $(E Z H 2, E E D, S U Z 12)$ are found in approximately $25 \%$ of T-ALL patients. Heterozygous loss-of-function mutations in individual PRC2 members have been identified to co-occur in a number of T-ALL patients suggesting that the PRC2 mutations likely operate as haploinsufficient tumor suppressors [25, 27]. Further work to characterize the phenotype of conditional deletion of individual PRC2 members will hopefully improve our understanding of the similarities and differences in the biological consequences of mutations in various PRC2 members.

Mutations in Polycomb-group associated proteins:

ASXL1 and the ASXL-BAP1 axis

ASXL1 is the human homolog of the Drosophila gene, Additional sex combs (Asx). Asx deletion results in a homeotic phenotype characteristic of both Polycomb (PcG) and Trithorax group (TxG) gene deletions [37] which led to the hypothesis that Asx has dual functions in silencing and activation of homeotic gene expression. Although ASXL1 appears to function in a dense network of physical interactions, we recently found that $A S X L 1$ appears to physically interact with the PRC2 complex in myeloid hematopoietic cells, and that the presence of ASXL1 appears to be associated with the global abundance of H3K27 methylation [4].

Somatic deletion and mutations in ASXL1 were initially identified by Gelsi-Boyer et al. [38] in patients with MDS and CMML. Although there is some controversy over whether certain reported variants in $A S X L 1$ represent true somatic mutations, it is clear that somatic mutations in ASXL1 are common in many of the same disorders as mutations in EZH2: MDS, myelofibrosis, MDS/MPN overlap disorders, as well as AML transformed from MDS [29]. Mutations in ASXL1 also appear to be associated with adverse overall survival in MDS and AML in multiple studies, raising the potential clinical importance of understanding the function of ASXL1 mutations and loss [9, 39, 40].

Based on characterization of $A S X L 1$ protein expression in myeloid leukemia cell lines bearing endogenous $A S X L 1$ mutations, we identified that $A S X L 1$ mutations are associated with loss of ASXL1 expression [4]. RNA-interference (RNA-i) mediated depletion of ASXL1 was associated with downregulation of $\mathrm{H} 3 \mathrm{~K} 27$ methylation while overexpression of ASXL1 was associated with global increased in H3K27 methylation in the mono-, di-, and trimethyl states (Fig. 2a). Intersection of H3K27me3 chromatin-immunoprecipitation sequencing (ChIP-Seq) data with geneexpression data from multiple isogenic cell types with ASXL1 loss revealed a set of genes that underwent upregulation following ASXL1 loss associated with loss of $\mathrm{H} 3 \mathrm{~K} 27 \mathrm{me} 3$, including the HOXA cluster of genes [4].

Shortly after the discovery of mutations in ASXL1, Fisher et al. [41] reported that constitutive deletion of Asxl1 appeared to have minimal effects on hematopoiesis. This work was performed through characterization of homozygous null Asxl1 knockout mice using a gene-trap vector associated with a very high rate of perinatal lethality, and without verifying eradication of Asxl1 expression at the protein level. Moreover, when Asxl1 was knocked down in vivo in the context of an NRasG12Dinduced myeloproliferative disorder, there was clear collaboration of Asxl1 loss with NRasG12D expression with hastening of death due to a lethal myeloproliferative/ myelodysplastic phenotype in mice with combined Asxl1 loss plus NRasG12D [4]. This was associated with a large increase in $5^{\prime} H O X A$ gene expression in bone marrow cells from mice with combined Asxl1 loss and NRasG12D expression and an increase in serial replating ex vivo. Thus, further work to characterize the effects of Asxl1 deletion using conditional deletion in the post-natal hematopoietic compartment will be critical to further our understanding of the effects of Asxl1 on hematopoiesis.

Recently, it was also shown that ASXL1 physically interacts with the deubiquitinase enzyme BAP1 and enhances the enzymatic activity of BAP14 [42]. Studies from Drosophila initially identified the ASXL1-BAP1 interaction and suggested that the ASXL1-BAP1 complex might be important in deubiquitinating H2A lysine 119 monoubiquitin (H2AK119Ub) [43]. While it is not clear that this function of the BAP1-ASXL1 complex is present 
A
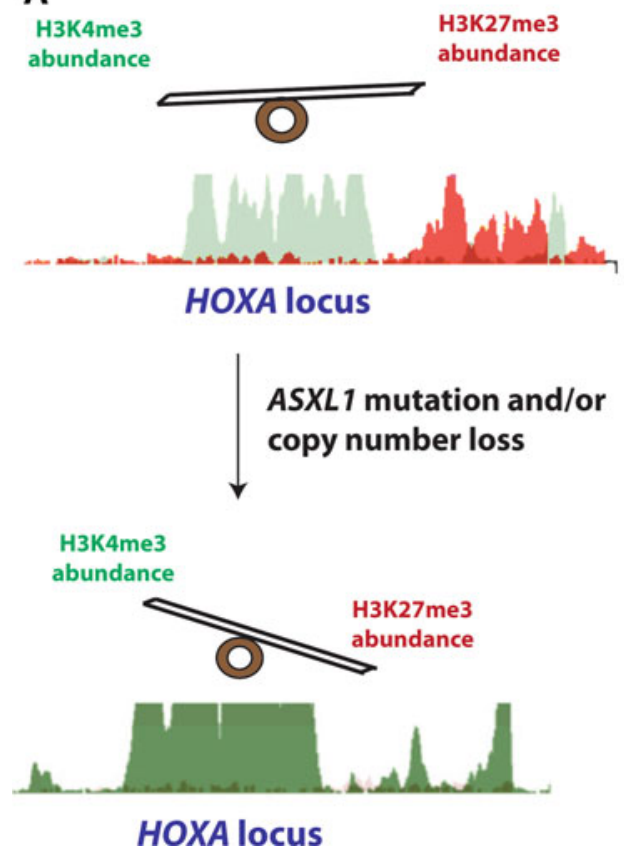

Fig. 2 The ASXL1-BAP1 axis. The level of ASXL1 expression appears to be strongly associated with the abundance of the transcriptionally repressive histone modification histone $\mathrm{H} 3$ lysine 27 trimethyl (H3K27me3) in myeloid leukemia cells (a). Loss of ASXL1 is associated with global loss of this modification despite the presence of the core members of the Polycomb repressive complex 2, the enzymatic complex necessary for methylation of H3K27. Thus, loss of ASXL1 by mutation or copy-number alteration is associated with a loss of H3K27me3 but persistence of other marks, such as the activating $\mathrm{H} 3 \mathrm{~K} 4 \mathrm{me} 3$ mark, at key genomic loci such as the HOXA

in mammals, it does appear that BAP1 and ASXL1 function together to deubiquitinate the transcriptional regulator HCF-1 and the O-GlcNAc transferase enzyme OGT [42] (Fig. 2b). Interestingly, conditional deletion of Bap1 from the hematopoietic compartment results in a striking MDS/ MPN overlap syndrome, and rare mutations as well as downregulation of BAPl are seen in patients with MDS [42]. BAP1-deficient cells have a clear loss of HCF-1 and OGT suggesting that ASXL1-BAP1 serve to stabilize the expression of these proteins. Further work to identify the role of HCF-1 and OGT in ASXL1-mutant myeloid malignancies may be enlightening and characterization of the effects of inhibiting the downstream sequelae of ASXL1/BAP1 loss may yield therapeutic insight for myeloid malignancies.

Trithorax gene alterations: MLL1 translocations/ mutations and $M L L 2$ mutations

Like the Polycomb group of proteins, the trithorax group of proteins is a group of proteins first described in Drosophila melanogaster, which are required for normal development
B

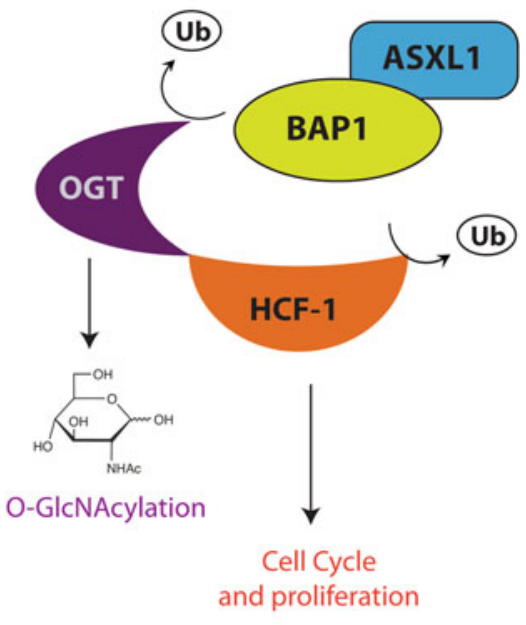

cluster. In addition to effects on H3K27me3, ASXL1 also physically interacts with BAP1. Together, the ASXL1-BAP1 complex serves as a dequbiquitinase which stabilizes the proteins OGT and HCF-1 through removal of ubiquitin. OGT is the sole enzyme responsible for addition of the sugar modification $O$-linked b-D- $N$-acetylglucosamine $(O-\mathrm{GlcNac})$ to proteins while HCF-1 is a protean transcriptional regulator that has been shown to influence cell cycle progression. While BAP1 mutations and downregulation are clearly associated with loss of HCF-1 and OGT, the association of ASXL1 levels with HCF-1 and OGT stability is currently unknown

and appear to be essential for the maintenance of normal, and possibly malignant, stem cell populations through the maintenance of expression of key genes. The mammalian mixed lineage leukemia (MLL) family consists of five family members (MLL1-5), which are the mammalian homologs of the Drosophila Trithorax protein; biochemical studies have shown that MLL members 1-4 function as histone H3 lysine 4 (H3K4) methyltransferases. MLL1 translocations result in an in-frame fusion of the aminoterminal portion of MLL1 to $>60$ different partners and occur in $\sim 10 \%$ adult de novo AML patients, $30-40 \%$ of patients with therapy-related AML, and $80 \%$ of infant leukemias. Since the discovery of MLL1 in 1992, both molecular alterations resulting in partial tandem duplications (MLL-PTD) as well as a series of in-frame translocations in MLL1 have been described in AML patients. MLL1-PTD mutations were the first molecular markers associated with adverse prognosis in AML patients and most MLL translocations are associated with poor outcome in patients with de novo AML [44, 45].

The most frequent MLL1 translocations (MLL-AF4, MLL-AF9, MLL-AF10, and MLL-ENL) result in 
recruitment of disruptor of telomeric silencing 1-like (DOT1L) to the fusion protein and acquisition of H3K79 methyltransferase activity with loss of H3K4 methyltransferase activity [46, 47]. Multiple studies have linked H3K79 methylation to positive transcriptional activation and as a unique mark for leukemogenic transformation [48, 49]. In fact, an experiment performed by Okada et al. [50] showed that artificial fusion and expression of MLL1DOT1L immortalizes hematopoietic progenitors. Moreover, MLL1 fusion proteins may activate leukemogenic genes through more than one mechanism [51]. The first mechanism of gene-expression activation involves the direct oligomerization of MLL1 fusion partners and translocation to the nucleus influencing transcription itself [52-54]. For example, mouse models of MLL1 fusion partners known to translocate to the nucleus, such as MLLGAS7 and MLL-AF1P, developed AML [52-54]. However, in the case where MLL fusion partners are nuclear proteins that influence transcription themselves, such as MLL-ENL and MLL-AF9, the onset of AML in mice was much more rapid, suggesting a more complex mechanism beyond simple oligomerization [54-56].

Another mechanism of transcriptional activation of MLL-fusion proteins may be through association with transcriptional activating proteins such as RNA polymerase II [57]. The most common MLL fusion partners contain a C-terminal transcriptional activation domain that appears to be important for oncogenesis $[58,59]$. It appears that the MLL fusion proteins recruit diverse complexes of proteins involved in transcriptional control and elongation to the promoters of $M L L$ target genes. These proteins are recruited through chromatin remodeling, in particular through the manipulation of the histone code.

The unique mechanism of MLL-PTD mutations associated with AML involves the in-frame partial tandem duplication of exons 5 through 11 without any partner fusion gene [60]. The occurrence of this rearrangement has been seen in 4-7 \% of patients with AML and is associated with poor prognosis [44, 45]. MLL-PTD results in an increase in histone $\mathrm{H} 3 / \mathrm{H} 4$ acetylation and $\mathrm{H} 3 \mathrm{~K} 4$ methylation within the Hoxa7 and Hoxa9 promoters, resulting in overexpression and as a consequence AML through a gain of function mutation [61]. In addition, the histone acetyltransferase cAMP response element binding protein (CBP) responsible for histone acetylation associates with MLL in a complex through its C-terminal transactivation domain, uniquely preserved in MLL-PTD [62]. The SET domain is also retained in the C-terminus of MLL-PTD, in contrast to other $M L L$ fusion genes found in AML, which has activity essential for H3K4 methylation [61]. Both the CBP and SET activities are crucial for Hox gene expression and indeed experiments with MLL-PTD show a correlation between increased $\mathrm{H} 3 \mathrm{~K} 4$ methylation and $\mathrm{H} 3 / \mathrm{H} 4$ acetylation and overexpression of Hoxa7 and Hoxa9, genes involved in leukemogenesis towards AML [61].

As reviewed elsewhere [51], MLL1 functions in a dense network of protein-protein interactions thought to be critical for its activity in normal cellular compartments and in leukemia cells (Fig. 3). This includes interactions with menin, the polymerase-associated factor complex (PAFc), and even interaction between translocated MLL1 and a wild-type copy of MLL1. The majority of translocations of MLL1 seen in AML/ALL patients result in a loss of the SET domain responsible for $\mathrm{H} 3 \mathrm{~K} 4$ methyltransferase activity. Importantly, many MLL fusion oncoproteins acquire H3K79 methyltransferase enzymatic activity through recruitment of H3K79 methyltransferase DOT1L. As such, therapeutic targeting of DOT1L and small molecule inhibition of MLL interactions with other critical mediators has been extensively pursued [63, 64].

Currently, the best-characterized inhibitor of DOT1L is EPZ004777. Development of EPZ004777 represents a remarkable proof-of-concept for epigenetic targeted agents. EPZ004777 was designed as a competitive inhibitor of S-adenosylmethionine (SAM), the universal donor of methyltransferase enzymatic reaction. Prior the development of EPZ004777, the only known histone methyltransferase inhibitors included chaetocin (inhibits the lysine methyltransferase $\mathrm{Su}(\mathrm{var}) 3-9)$, DZNep (inhibits H3K27 methylation), and BIX-01294 (an arginine specific methyltransferase inhibitor). All three compounds suffered from their lack of specificity and thus have not entered clinical development. For instance, DZNep interferes with AdoMet-AdoHcy metabolism and causes reduced methylation indirectly. Despite the universality of SAM as a methyl donor, EPZ004777 has a remarkable preferential selectivity for DOT1L over other histone lysine or arginine methyltransferases [63]. This results in selective inhibition leukemia cell lines with specific MLL1 translocations compared with cell lines without MLL1 translocations. Recently, additional small molecule inhibitors of DOT1L have been described by creating stable molecules which mimic S-adenosylhomocysteine, one of the SAM reaction products which is a known but unstable inhibitor of DOT1L [64]. Further studies of structurally similar compounds for targeting of MLL1-translocations, as well as other SAM-dependent enzymes, may hopefully yield an array of methyltransferase-targeted therapeutic agents.

As mentioned above, in addition to DOT1L, MLL1 is dependent on a large number of protein-protein interactions for transcriptional regulation as well as leukemogenesis (Fig. 3). One such interaction, which appears remarkably tractable as a therapeutic target in preclinical studies, is the interaction between MLL and PAFc. Muntean et al. and Milne et al. have demonstrated that PAFc interacts with MLL1 via the highly conserved CxxC-RD2 
*

Potentially therapeutically

targetable protein-protein interactions

* Therapeutically
targetable enzymes

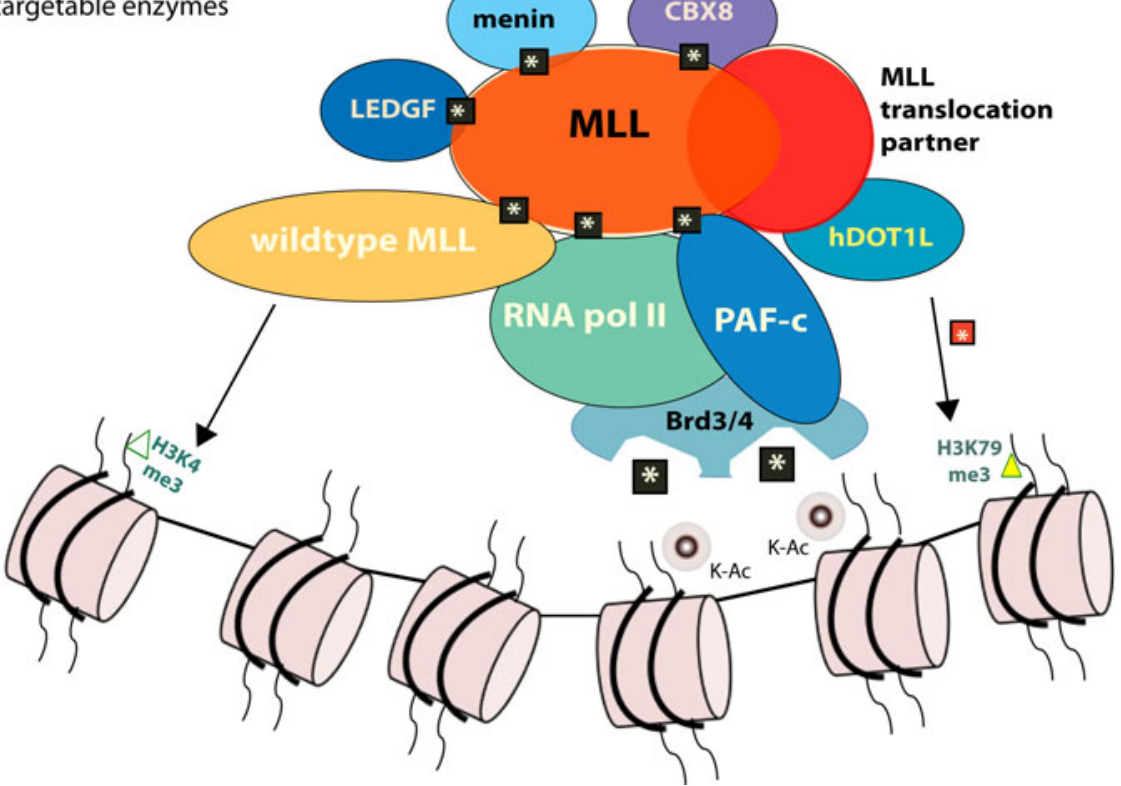

Fig. 3 Therapeutic targeting of MLL translocated oncoproteins in leukemogenesis. The leukemogenicity of translocated MLL is dependent on an intricate number of protein-protein interactions. Detailed understanding of these interactions has resulted in several potential therapeutic strategies involving for disruption of these critical interactions. This includes targeting interactions with menin, LEDGF, CBX8, wild-type MLL, and PAFc. Several of these proteins, themselves recruit additional enzyme activities to the complex with translocated MLL, such as the recruitment of the E1 ubiquitin ligase

region $[65,66]$. PAFc plays a critical role initiating, elongating and terminating mRNA transcription as well as in histone $\mathrm{H} 2 \mathrm{~B}$ monoubiquitination. MLL1, through its interactions with PAFc as well as other molecules in a separate complex called the super elongation complex (SEC), has been recently shown to interact with BRD3 and BRD4 [67]. BET proteins bind acetylated histones via a highly conserved tandem bromodomain at their $\mathrm{N}$-terminus and thereby activate gene transcription. Recently, multiple investigators have converged on the therapeutic efficacy of different novel, small molecular inhibitors of the deep, largely hydrophobic acetyl lysine binding pocket of BRD4: JQ1 [68-70], GSK525762A (referred to as I-BET) [71], and GSK1210151A (referred to as I-BET151) [72]. So far these molecules have been found to be efficacious in a diverse array of human disorders including patients with BRD4-NUT positive midline carcinomas [69], and multiple myeloma [68]. The concept of bromodomain inhibition as a therapy for AML was found recently by two separate groups using very disparate approaches. Zuber et al. [70] performed an RNAi screen to identify genes critical for survival of MLL-AF9 driven leukemias. This approached complex BRE1/RAD6 by PAFc (not shown). PAFc also bridges translocated MLL to the bromodomain-containing proteins, Brd3/4. Therapeutic interference with Brd3/4-acetyl lysine recognition has proven to be a very promising therapeutic strategy in AML preclinical studies. In addition to these interactions, multiple MLL translocation partners are well characterized as recruiting DOT1L, an enzyme with H3K79 methyltransferase activity. This has also led to the development of several small-molecule inhibitors of DOT1L for therapeutic targeting of translocated MLL

identified BRD4 to be a critical mediator of MLL-AF9 leukemia cell growth and survival using genetic and pharmacologic BRD4 inhibition. Dawson et al. [72] utilized a proteomics approach to identify the common proteins interacting with I-BET, BRD2/3/4, and acetylated histone lysine tails (K5ac, K8ac, and K12ac). This approach led to the identification of BRD3 and BRD4 as part of the PAFc and SEC and provided the rationale for BET bromodomain inhibition in human and murine MLL translocated leukemias. The discovery of utility of bromodomain inhibition as a therapeutic strategy in human disease is important proof-of-concept of the utility of targeting protein-protein interactions to reverse epigenetic alterations in myeloid malignancies and in other disease contexts.

In addition to mutations and translocations in $M L L 1$ in AML, mutations in MLL2 have recently been discovered in the majority of patients with follicular lymphoma, as well as a significant proportion of patients with DLBCL [73-75]. MLL2 mutations are strikingly present in as much as $89 \%$ of patients with FL, making MLL2 the most common genetic alteration in FL besides the $\mathrm{t}(14 ; 18)(\mathrm{q} 32 ; \mathrm{q} 21)$ 
translocation. MLL2 mutations are also present in 24-32\% of patients with DLBCL, and appear to cluster with the GCB-like subtype of DLBCLs (as do EZH2 activating point mutations). The mutations in MLL2 appear throughout the open-reading frame and are occasionally bi-allelic and/or associated with loss-of-heterozygosity, suggesting that the MLL2 mutations are associated with loss of MLL2 expression. How exactly MLL2 alterations might contribute to lymphomagenesis is quite unclear currently. Many of the MLL2 mutations seen in patients with lymphomas resemble the MLL2 mutations seen in patients with the developmental disorder Kabuki Syndrome (a condition in which the predisposition to cancer development is not currently understood) [76]. Conditional deletion of Mll2 in mice has been studied but most in vivo studies have focused on the effect of Mll2 deletion on development, embryonic stem cell pluripotency, and development of reproductive systems [77, 78]. Conditional deletion of Mll2 in a panhematopoietic or B-cell specific context will hopefully give some insight into the role of Mll2 loss on hematopoiesis.

Histone acetyltransferase alterations in leukemias and lymphomas: CREBBP and EP300 mutations

In addition to mutations in EZH2 and $M L L 2$, recent genomic studies in patients with DLBCL and FL have also identified frequent mutations in the transcriptional coactivator $C R E B B P$ and the highly related gene $E P 300$ [7, 73, 74]. Both CREBBP and EP300 function as (1) molecular scaffolds for coupling a large number of transcription factors, (2) histone acetyltransferases for all four core histones, (3) acetyltransferases for non-histone proteins such as BCL6, p53, and GATA-1, and (4) ubiquitin ligases for p53 (reviewed in [79]). Pasqualicci et al. identified mutations in CREBBP and/or EP300 in $39 \%$ of DLBCL patients and $41 \%$ of FL patients and reports followed by Morin et al. and Lohr et al. confirming recurrent CREBBP/ EP300 mutations in these same lymphomas [7, 73, 74].

Mutations in CREBBP and EP300 most commonly occur in a heterozygous fashion throughout the open-reading frame, suggesting that the mutations result in loss-of-function, and that loss of acetyltransferase activity might promote lymphomagenesis in a haploinsufficient manner. Further work evaluating the function of wild type versus mutant forms of CREBBP to acetylate BCL6 and p53 in vitro revealed a clear impairment in acetyltransferase activity of CREBBP mutants [7]. Moreover, the authors tested the transcriptional and acetyltransferase activity of exogenously introduced wild-type or mutant forms of $C R E B B P$ into murine embryonic fibroblasts from mice with Crebbp and Ep300 double knockout alleles. This analysis revealed clear upregulation of Crebbp target genes with expression of wild-type Crebbp, but failure of transcription as well as histone acetyltransferase activity of the mutant forms of CREBBP [7].

Interestingly, many of the somatic mutations in $C R E B B P$ and EP300 found in lymphoma patients are similar to the CREBBP and EP300 mutations found to underlie the developmental syndrome, Rubinstein-Taybi syndrome (RTS) [80]. Patients with RTS are known to be at increased risk of malignancies, including malignancies derived from nervous-tissue, leukemias, and lymphomas, but at an unclear frequency [81]. Mice with constitutive heterozygous loss of $C R E B B P$ develop decreased numbers of $\mathrm{B}$ and $\mathrm{T}$ lymphocytes as well as hematologic malignancies of myeloid and lymphoid origin with advanced age at an increased frequency compared to wild-type counterparts [82]. In many cases, the $C R E B B P$ heterozygous knockout tumors were found to have lost the remaining wild-type copy of Crebbp indicating that Crebbp function as a bona fide tumor suppressor in the hematopoietic system. Before the discovery of CREBBP or EP300 mutations in lymphoma, $\mathrm{Xu}$ et al. [83] studied the effects of conditional deletion of CREBBP and EP3OO alone and in combination with one another in the B-cell compartment using CD19 Cre recombinase. This analysis revealed that deletion of either CREBBP or EP300 alone resulted only in modest decrements in B-cell numbers. Mice with conditional deletion of both CREBBP and EP300 at the pro-Bcell stage had negligible defects in B-cell development, but it appeared that B-lymphocytes with combined $C R E B B P /$ EP300 deletion may have been selected against in vivo due to intolerance of the lack of these two genes. Thus, it is not yet clear why mutations in CREBBP or EP300 appear so enriched in patients with FL and DLBCL. Efforts to understand if drugs targeting the aberrant acetylation in $C R E B B P / E P 300$ mutant lymphomas may have efficacy in this genetic subset of tumors are needed.

Before the discovery of somatic mutations and copy number loss of $C R E B B P / E P 300$ in lymphomas and ALL, rare translocations involving $C R E B B P$ and $E P 300$ were identified in patients with AML. In fact, both $C R E B B P$ and EP300 have been identified as translocation partners with yet another histone acetyltransferase, $\operatorname{MOZ}(\mathrm{t}(8 ; 16)(\mathrm{p} 11 ; \mathrm{p} 13)$ (MOZ-CREBBP) [84] and $\mathrm{t}(8 ; 22)(\mathrm{p} 11 ; \mathrm{q} 13)$ (MOZEP300)) [85]. $M O Z$ is also occasionally translocated to TIF2 in the $\operatorname{inv}(8)(\mathrm{p} 11 \mathrm{q} 13)$ alteration in AML patients. Although the MOZ-TIF2 fusion protein has been clearly demonstrated to efficiently transform myeloid progenitor cells in vitro and in vivo [86], how any of the alterations in $M O Z, C R E B B P$, or EP3O0 actually impact transcription or specific patterns of histone acetylation will need to be investigated in further detail. 


\section{Mutations affecting DNA cytosine modifications}

DNMT3A mutations: DNA methylation and regulation on the hematopoietic stem cell compartment

The family of DNA methyltransferase enzymes is comprised of three members: Dnmt1, Dnmt3a, and Dnmt3b [87]. These enzymes function in the key epigenetic modification of DNA methylation of $\mathrm{CpG}$ islands, important in influencing tissue-specific gene expression [88]. Recently, mutations in DNMT3A have been found to occur in approximately $20-22 \%$ of de novo AML patients [89-91]. DNMT3A mutations have been found enriched among the same cytogenetically defined intermediate-risk AML patients, which also carry TET2 and IDHI/2 mutations. Intriguingly, mutations in DNMT3A, TET2, and IDHI/2 have also recently been found in human T-cell lymphomas.

While missense, nonsense, and frameshift mutations in DNMT3A occur throughout the open-reading frame, a single heterozygous point mutation at Arg-882 in DNMT3A has emerged as the single most frequent mutation in DNMT3A [89]. Previous work by Yamashita et al. [90] revealed that the cell-free methyltransferase activity of DNMT3A is hampered by the Arg-882 mutation, however, this work was not performed in the presence of the wildtype DNMT3A protein as would be expected in vivo. More recently, Holz-Schietinger et al. [92] have performed a careful biochemical characterization of DNMT3AR882 and suggest that mutations at Arg-882 disrupt the ability of DNMT3A molecules to dimerize with one another and form tetramers with DNMT3L, a process critical for the catalytic activity of DNMT3A.

Detailed characterization of the effects of conditional post-natal deletion of Dnmt3a in mice has revealed a role for Dnmt3a in regulation of long-term hematopoietic stem cell (LT-HSC) function and number. Challen et al. [93] first identified clear expression of Dnmt3a in the LT-HSC compartment with a striking downregulation in expression with hematopoietic differentiation. Although deletion of Dnmt3a had minimal effects on hematopoiesis in primary knockout (Mx1Cre Dnmt3a ${ }^{-/-}$) mice or even in primarily transplanted recipient mice, Challen et al. [93] noticed that with continued competitive serial transplantation of Dnmt3a-deficient HSC's that there was a striking increase in the contribution of Dnmt3a-null cells to the LT-HSC pool but not to more committed myeloid/lymphoid progenitors, indicating that the effect of Dnmt3a ablation is restricted to the most primitive HSC's. Moreover, blood production in the serially transplanted mice was not representative of the stem cell expansion of the Dnmt3a-null cells, suggesting a possible differentiation defect. This data suggest that Dnmt3a loss mostly affects the LT-HSC's, possibly by promoting self-renewal over differentiation: a delicate balance that is tipped towards self-renewal in the process of leukemogenesis.

Use of the Dnmt3a knockout mouse model to study the effect of Dnmt3a loss on methylation has yielded somewhat unexpected findings. Liquid chromatography-mass spectrometry and reduced representation bisulfite sequencing revealed no global difference in methylation between Dnmt3a wild-type and null HSC's [93]. Bisulfite sequencing combined with transcriptomic analysis revealed both hyperand hypomethylation of target genes in tertiary-transplanted HSC's with hypomethylation of a set of genes important for HSC multipotency including RUNX1, GATA3, PBXI, FOXO1, and CDKNIa [93].

Although the above studies have been enlightening for our understanding of the role of DNMT3A in regulating HSC number and function, further studies to define the contribution of DNMT3A loss and mutations to leukemogenesis will be helpful as DNMT3A loss alone does not appear sufficient to generate AML [93]. The DNMT3A R882 variant will be of particular interest because it has been shown to be most prevalent and associated with worsened overall survival in AML in multiple cohorts [9, 89].

\section{TET2 mutations}

Ten-eleven translocation 2 (TET2), located on chromosome 4 at band $4 \mathrm{q} 24$, is affected by loss-of-function mutations or copy-number loss in 10-20\% of MDS patients [94, 95], up to $23 \%$ of AML patients [9, 95], and 9-16\% of patients with chronic MPNs [94, 95]. The TET proteins are $\mathrm{Fe}(\mathrm{II})$ and $\alpha$-ketoglutarate-dependent enzymes which iteratively oxidize 5-methylcytosine $(5-\mathrm{mc})$ to 5-hydroxymethylcytosine (5-hmc) [96], followed by 5-formylcytosine (5-fC) and 5-carboxylcytosine (5-caC) [96]. Based on this function, it is predicted that loss-offunction mutations in TET2 would result decreased global 5-hmC levels and increased 5-mC levels [3]. While the effect of mutations in TET2 on global loss of 5-hmC is clear from the work of Ko et al. [3] and recent work from our own group [97], the effects of TET2 loss on global 5-mC have been discrepant among studies. This literature has been extensively reviewed recently [98]. Additional studies using primary patient materials and tissue from Tet2 KO mice to simultaneously measure 5-mC, 5-hmC, and transcription will hopefully clarify the effects of TET2 mutations on DNA methylation and the relationship between 5-hmC and transcription. Moreover, very little is known currently about the role of 5-fC and 5-caC beyond their function as possible intermediates in the demethylation of DNA. Further work to determine the stability of these moieties, their genome-wide distribution, and possible relationship to gene expression are greatly needed. 
In contrast with the discrepant reports on the effects of TET2 loss on DNA methylation, it has become clear from more than five models of in vivo Tet 2 deletion that Tet 2 is a critical regulator of HSC self-renewal (the in vivo models of Tet 2 deletion have been extensively reviewed recently elsewhere [99]). Nearly all of these Tet 2 knockout models have revealed that deletion of Tet2, whether in a conditional, hematopoietic-specific manner, or in the germline, results in expansion of the hematopoietic-stem progenitor compartment and increased hematopoietic stem cell selfrenewal shortly after deletion [100-103]. Overt myeloproliferation is also evident following Tet 2 deletion in vivo but with a latency of at least 3-6 months, suggesting that the acquisition of additional collaborating events is required for disease initiation and progression in vivo.

In the initial discovery of TET2 mutations in $J A K 2 \mathrm{~V} 617 \mathrm{~F}-$ mutant MPN patients, evidence from genotyping the $J A K 2 \mathrm{~V} 617 \mathrm{~F}$ mutation and TET2 mutation in ex vivo colonies grown in methylcellulose from MPN patients suggested that TET2 mutations were likely to occur early in MPN development [94]. In many cases TET2 mutations appear to precede the acquisition of the $J A K 2 \mathrm{~V} 617 \mathrm{~F}$ mutation. Recently, data from several studies have provided further evidence that TET2 mutations may occur very early in the development of myeloid malignancies and may actually be associated with the development of clonal hematopoiesis in the absence of overt malignancy development [104, 105]. For instance, Jan et al. [105] have recently screened for mutations in sorted populations of leukemic blasts from AML patients bearing the FLT3-ITD mutation and residual HSC's to identify what mutations present in the leukemic population might have occurred in what are thought to be pre-leukemic normal HSC's (normal HSC's were defined by immunophenotype as lineagenegative $\mathrm{CD}_{3}{ }^{+} \mathrm{CD}^{-} 8^{-} \mathrm{TIM}^{-}{ }^{-} \mathrm{CD}^{-} 9^{-}$cells and were demonstrated to result in engraftment in immunocompromised mice). While mutations in FLT3 were only seen in the frankly leukemic cells, mutations in TET2 were seen in the pre-leukemic HSC compartment. Interestingly, one patient was found to have a small population of LT-HSC cells bearing no TET2 mutation followed by increasingly larger populations of LT-HSCs with single TET2 mutation and bi-allelic TET2 mutations. This data suggest that TET2 mutations occurred at the LT-HSC level and resulted in clonal expansion of the HSC compartment with later transformation to AML. More recently, we performed exome sequencing on elderly individuals with clonal hematopoiesis based on X-chromosome inactivation studies [104]. This revealed somatic TET2 mutations in the myeloid compartment of a proportion of patients with age-associated skewing of hematopoiesis. None of the individuals with TET2 mutations and clonal hematopoiesis had overt hematopoietic malignancy and one individual with a TET2 mutation and clonal hematopoiesis was observed to later develop a $J A K 2 \mathrm{~V} 617 \mathrm{~F}$ mutations and primary myelofibrosis.

The summary of human genetic data and data form murine studies suggest that TET2 mutations frequently occur in LT-HSC's and result in expansion of the HSC compartment without necessarily resulting in immediate hematopoietic transformation (Fig. 4). Future work to identify genetic targets of TET2 mutations should be helpful in furthering our understanding of how TET2 mutations contribute to clonal expansion and eventual malignant proliferation.

\section{IDH1/IDH2 mutations}

IDH1, isocitrate dehydrogenase 1, is a key cytosolic enzyme of the tricarboxylic acid (TCA) cycle, with the homolog, IDH2, playing the same role in the mitochondria. The function of IDH1/2 is to decarboxylate isocitrate to $\alpha$-ketoglutarate $(\alpha-\mathrm{KG})$, producing NADP in the process. Mutations in IDHI/2 were identified in AML and have subsequently been seen much less commonly in other myeloid malignancies, such as MDS and MPN [106, 107]. Mutations in $I D H 1$ and $I D H 2$ are heterozygous and occur at highly conserved arginine residues analogous in both isotypes of the gene. The fact that these mutations are heterozygous suggests that there may be a gain of function in the mutated allele while the wild-type allele maintains normal function for cellular metabolism [108, 109]. Indeed, further studies have shown that mutations in $I D H 1 / 2$ cause the conversion of $\alpha$-ketoglutarate to 2-hydroxyglutarate (2-HG) [108, 109]. Patients with IDHI/2 mutant AML have markedly elevated levels of $2-\mathrm{HG}$ in the serum suggesting that it is a diagnostic biomarker [108].

In collaboration with the laboratories of Ari Melnick and Craig Thompson, we initially identified that TET2 mutations rarely co-occur with mutations in $I D H 1 / 2$ [110, 111]. In a study of 398 AML samples from the ECOG E1900 cohort, IDH1/2 mutant AML was associated with consistent and aberrant hypermethylation signatures in promoter sites important in myeloid cell maturation and leukemogenesis [97]. Further, similar global hypermethylation signature was seen in patients harboring TET2 mutations and both TET2 and IDH1/2 mutations were mutually exclusive in this AML cohort [97]. Moreover, we initially identified that loss of Tet 2 or expression of mutant forms of IDHI/2 had similar effects on hematopoietic stem cell populations in short-term assays and on the genome-wide pattern of DNA methylation. Stable knockdown of Tet 2 in murine bone marrow resulted in a similar increase in 5-mC levels, as did expression of mutant IDH1/2 [97]. In addition, expression of $\mathrm{IDH} 2$ mutants as well as loss of Tet2 similarly impaired myeloid differentiation [97]. Since TET2 enzymes depend on $\alpha-\mathrm{KG}$ for their activity and the 


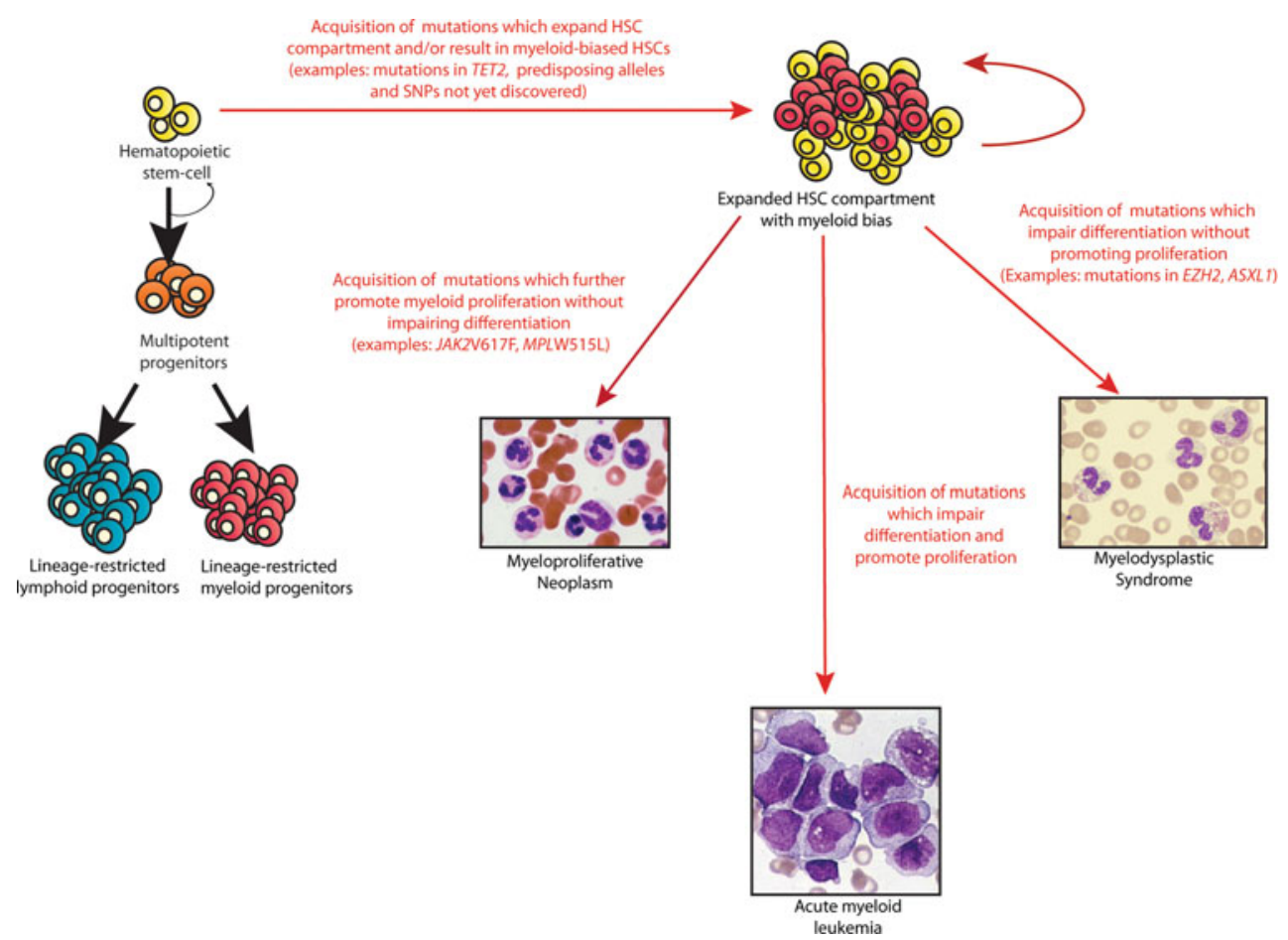

Fig. 4 Multistep model of myeloid malignancy pathogenesis. Normal hematopoiesis proceeds from a small pool of hematopoietic stem cells (HSC's) with limitless self-renewal to produce more differentiated lymphoid and myeloid progenitors with more restricted differentiation potential (left). Ageing is known to be associated with the acquisition of HSC's with myeloid-bias and a decreased in lymphoid progenitor cells (right). The discovery of novel mutations in patients with myeloid malignancies suggests the presence of acquired

mutational byproduct of IDHI/2 mutations, $2-\mathrm{HG}$, is a competitive inhibitor of $\alpha-\mathrm{KG}$, we hypothesized that the mutual exclusivity of TET2 and IDHI/2 mutations was likely due to the effects of 2-HG on disrupting the activity of the normal function of TET2. Soon after this observation, $\mathrm{Xu}$ et al. [112] identified that 2-HG can directly inhibit TET2 function.

In terms of understanding the biological ramifications of IDH1/2 mutations on hematopoiesis in more detail, Sasaki et al. [113] have recently described the creation and phenotype of a conditional Idh1(R132H) knockin mouse model. Following conditional expression of Idh1R132H using the lox-stop-lox system throughout the hematopoietic system using vav-Cre recombinase (vav-KI) or in only the myeloid cells using LysM Cre recombinase (LysM-KI), the authors identified that the mice expressing the $\mathrm{R} 132 \mathrm{H}$ mutation using either LysM-KI or vav-KI produced tenfold higher serum 2-HG than their wild-type littermates. Despite this elevation in serum 2-HG, the LysM-KI mice appeared to have a normal lifespan and were viable and fertile. At the same time, conditional expression of Idh1R132H using either system resulted in an age-dependent splenomegaly due to extramedullary hematopoiesis genetic events with age, which may be associated with myeloid skewing of HSC's and promote further malignant transformation. Mutations in TET2 which result in clonal myeloid proliferation in humans and in mice with frank myeloid malignancy developing only after a long latency are an example of such an acquired somatic mutation which may be such an early event in myeloid malignancy pathogenesis. Acquisition of additional genetic events following these early events may result in a clearer malignant phenotype

and a coincident development of a less cellular bone marrow than in age-matched wild-type counterparts. Despite the decreased cellularity of the marrow in the $\mathrm{KI}$ mice, there was an expansion in the HSC compartment [lineage-negative, $\mathrm{Sca}^{+}, \mathrm{c}-\mathrm{KIT}^{+}(\mathrm{LSK})$ cells] in these mice due to an expansion of the multipotent progenitor population specifically (the LSK CD $150^{-} \mathrm{CD} 48^{+}$population). This suggests that mutant Idh1 actually results in an age-dependent blockade of hematopoietic differentiation.

As noted previously, mutations in IDH1/2 are mutually exclusive with mutations in TET2 [97] and mice with deletion of Tet2 experience a clear increase in the HSC population with robust increase in self-renewal [100-103]. It is not yet clear whether the HSC's from mice with expression of mutant Idh1 have a similar increase in selfrenewal. In the study by Sasaki et al. [113] competitive transplantation of the LysM-KI Idh1R132H nucleated bone marrow cells did not reveal a clear competitive advantage compared with their wild-type counterpart cells. Further work in serial competitive transplantation and limiting dilution analyses may be helpful in identifying the effects of mutant IDH1/2 expression on HSC function and phenotype. 
In addition to the above studies which have focused on the role of $I D H 1 / 2$ mutations in myeloid malignancies, a series of studies have recently identified mutations in IDH1/2, TET2, and DNMT3A in patients with angioimmunoblastic T-cell lymphomas (AITL) and peripheral T-cell lymphomas, not otherwise specified (PTCL-NOS) (the two most common peripheral T-cell lymphomas in Western countries) [114-116]. Interestingly, the initial discovery of TET2 mutations in PTCL identified that AITCL and PTCLNOS cases with TET2 mutations very frequently also harbored co-occurring DNMT3A mutations [116]. In an extended series by Lemonnier et al. [115] it appears that TET2 mutations are present in $47 \%$ of AITL patients and $38 \%$ of PTCL-NOS patients. Notably, the PTCL-NOS patients who were TET2 mutated appeared to have features of Th follicular cells, which are thought to give rise to AITL and to a subset of PTCL cases. Thus, it appears that TET2-mutant PTCL-NOS lymphomas may actually more closely resemble AITL than TET2 wild-type PTCL-NOS lymphomas. In addition to TET2 mutations, IDH $1 / 2$ mutations were found to be present in $20 \%$ of AITL by the same group. Together, this data suggest the likely importance of the deregulation of DNA cytosine methylation, hydroxymethylation, and/or demethylation in T-cell lymphomagenesis. Further work to identify the genome-wide patterns of 5-mC and 5-hmC in TET2 mutant and wild-type PTCL and AITCL samples may yield important insights into the pathogenesis of these previously poorly understood disorders.

In addition to disrupting the activity of the TET family of 5-mC hydroxylases, a number of additional $\alpha-\mathrm{KG}$ dependent dioxygenases exist, including the Jumonji family of histone lysine demethylases and the prolyl hydroxylases. 2-HG inhibits three classes of enzymes belonging to the Jumonji family: peptidylarginine deiminase, lysine specific demethylase 1, and the Jumonji C domain family of histone demethylases (JHDM) [112, 117]. The lysine-specific demethylase 1 removes methyl groups from $\mathrm{H} 3 \mathrm{~K} 4 \mathrm{me}$ and $\mathrm{H} 3 \mathrm{~K} 9$ me using flavin while the Jumonji $\mathrm{C}$ domain requires $\mathrm{Fe}(\mathrm{II})$ and $\alpha-\mathrm{KG}$ as cofactors [118]. The JHDM has been shown to remove lysine methylation marks on a number of histone lysines containing mono-, di-, and tri-methylations [119]. Concurrently, in the presence of $I D H 1 / 2$ mutations there is significant hypermethylation of many of same histone lysines that JHDM acts on. These findings contribute to the theory that hypermethylation of DNA and epigenetic modification of histone lysine and arginines play an important role in pathogenesis of AML. Thus, the epigenetic changes which occur in response to mutations in $I D H 1 / 2$ resulting in myeloid malignancy are at least twofold: (1) $I D H 1 / 2$ mutations result in alterations in DNA cytosine modifications and DNA global hypermethylation based on their disabling effect on TET family of proteins; (2) similarly, IDHI/2 mutations impair the Jumonji family of histone lysine demethylases (JHDM) resulting in increased histone lysine methylation at a number of residues [112]. In both cases, the proteins which IDH1/2 mutations impair are dependent on $\alpha-\mathrm{KG}$.

Given that $I D H 1 / 2$ mutations lead to a gain of function mutation, it may be possible to design small molecule inhibitors that specifically block synthesis of 2-HG, with therapeutic response monitored through serum 2-HG levels and epigenetic patterning. Notably, two recent reports found that the $(R)$-enantiomer of $2-\mathrm{HG}[(R)-2 \mathrm{HG}]$ may actually serve as a cofactor for the activation of the EGLN family of prolyl hydroxylases [120, 121]. In both reports, the authors revealed that the oncogenicity of $I D H 1$ mutants in neural and hematopoietic cells may depend on the increased activity of EGLN, an $\alpha-K G$ dependent prolyl hydroxylase that normally marks the oxygen labile subunit of the transcription factor hypoxia-inducible factor (HIF) for proteasomal degradation. These data suggest that therapeutic targeting of EGLN may also be effective in the treatment of $I D H$ mutant disease.

\section{Conclusion}

Genomic discovery efforts in patients with hematological malignancies have been critical in identifying a recurrent theme of mutations in epigenetic modifiers in patients with leukemias and lymphomas. Although a catalog of such alterations now exists and clinical correlative studies are beginning to decipher potential clinical genotypephenotype associations, a number of important questions are open to investigation. For instance, in many cases, identifying the biological ramifications of mutations in detail in a number of epigenetic modifiers has not yet been performed. Studies in mice to conditionally activate or delete these genes alone, and in combination with other epigenetic modifiers, will hopefully inform our understanding of the impact of these alterations on hematopoiesis. Moreover, these models may help to identify specific genetic targets of chromatin dysregulation in tumors with specific alterations. In most cases, specific genetic targets linked to hematopoietic transformation following mutations in individual epigenetic modifiers remain unknown. Increased efforts to integrate mutational studies with epigenomic and transcriptomic profiling may help to delineate genetic targets responsible for malignant transformation following perturbations in epigenetic modifiers. Finally, the identification of the critical role of alterations in specific epigenetic pathways in these disorders will hopefully continue to inform novel therapeutic strategies. 


\section{References}

1. Figueroa ME, Skrabanek L, Li Y, et al. MDS and secondary AML display unique patterns and abundance of aberrant DNA methylation. Blood. 2009;114(16):3448-58.

2. Jiang Y, Dunbar A, Gondek LP, et al. Aberrant DNA methylation is a dominant mechanism in MDS progression to AML. Blood. 2009;113(6):1315-25.

3. Ko M, Huang Y, Jankowska AM, et al. Impaired hydroxylation of 5-methylcytosine in myeloid cancers with mutant TET2. Nature. 2010;468(7325):839-43.

4. Abdel-Wahab O, Adli M, Lafave LM, et al. ASXL1 mutations promote myeloid transformation through loss of PRC2-mediated gene repression. Cancer Cell. 2012;22(2):180-93.

5. Morin RD, Johnson NA, Severson TM, et al. Somatic mutations altering EZH2 (Tyr641) in follicular and diffuse large B-cell lymphomas of germinal-center origin. Nat Genet. 2010;42(2): $181-5$.

6. Dawson MA, Bannister AJ, Gottgens B, et al. JAK2 phosphorylates histone H3Y41 and excludes HP1alpha from chromatin. Nature. 2009;461(7265):819-22.

7. Pasqualucci L, Dominguez-Sola D, Chiarenza A, et al. Inactivating mutations of acetyltransferase genes in B-cell lymphoma. Nature. 2011;471(7337):189-95.

8. Mullighan CG, Zhang J, Kasper LH, et al. CREBBP mutations in relapsed acute lymphoblastic leukaemia. Nature. 2011;471 (7337):235-9.

9. Patel JP, Gonen M, Figueroa ME, et al. Prognostic relevance of integrated genetic profiling in acute myeloid leukemia. N Engl J Med. 2012;366(12):1079-89.

10. Bejar R, Stevenson K, Abdel-Wahab O, et al. Clinical effect of point mutations in myelodysplastic syndromes. N Engl J Med. 2011;364(26):2496-506.

11. Lewis EB. A gene complex controlling segmentation in Drosophila. Nature. 1978;276(5688):565-70.

12. Margueron R, Reinberg D. The Polycomb complex PRC2 and its mark in life. Nature. 2011;469(7330):343-9.

13. Cao R, Wang L, Wang H, et al. Role of histone H3 lysine 27 methylation in Polycomb-group silencing. Science. 2002;298 (5595):1039-43.

14. Czermin B, Melfi R, McCabe D, et al. Drosophila enhancer of Zeste/ESC complexes have a histone H3 methyltransferase activity that marks chromosomal Polycomb sites. Cell. 2002; 111(2):185-96.

15. Kuzmichev A, Nishioka K, Erdjument-Bromage H, et al. Histone methyltransferase activity associated with a human multiprotein complex containing the Enhancer of Zeste protein. Genes Dev. 2002;16(22):2893-905.

16. Muller J, Hart CM, Francis NJ, et al. Histone methyltransferase activity of a Drosophila Polycomb group repressor complex. Cell. 2002;111(2):197-208.

17. Varambally S, Dhanasekaran SM, Zhou M, et al. The Polycomb group protein EZH2 is involved in progression of prostate cancer. Nature. 2002;419(6907):624-9.

18. Varambally S, Cao Q, Mani RS, et al. Genomic loss of microRNA-101 leads to overexpression of histone methyltransferase EZH2 in cancer. Science. 2008;322(5908):1695-9.

19. McCabe MT, Graves AP, Ganji G, et al. Mutation of A677 in histone methyltransferase EZH2 in human B-cell lymphoma promotes hypertrimethylation of histone H3 on lysine 27 (H3K27). Proc Natl Acad Sci USA. 2012;109(8):2989-94.

20. Majer CR, Jin L, Scott MP, et al. A687V EZH2 is a gain-offunction mutation found in lymphoma patients. FEBS Lett. 2012.

21. Sneeringer CJ, Scott MP, Kuntz KW, et al. Coordinated activities of wild-type plus mutant EZH2 drive tumor-associated hypertrimethylation of lysine 27 on histone H3 (H3K27) in human B-cell lymphomas. Proc Natl Acad Sci USA. 2010; 107(49):20980-5.

22. Yap DB, Chu J, Berg T, et al. Somatic mutations at EZH2 Y641 act dominantly through a mechanism of selectively altered PRC2 catalytic activity, to increase H3K27 trimethylation. Blood. 2011;117(8):2451-9.

23. Berg T, Yap D, Thoene S, et al. Mutated EZH2 collaborates with Myc in indcuing lymphoma in a mouse model (Abstract 227). Blood. 2011;118.

24. Ernst T, Chase AJ, Score J, et al. Inactivating mutations of the histone methyltransferase gene EZH2 in myeloid disorders. Nat Genet. 2010;42(722):6.

25. Ntziachristos P, Tsirigos A, Van Vlierberghe P, et al. Genetic inactivation of the Polycomb repressive complex 2 in $\mathrm{T}$ cell acute lymphoblastic leukemia. Nat Med. 2012;18(2):298-301.

26. Simon C, Chagraoui J, Krosl J, et al. A key role for EZH 2 and associated genes in mouse and human adult T-cell acute leukemia. Genes Dev. 2012;26(7):651-6.

27. Zhang J, Ding L, Holmfeldt L, et al. The genetic basis of early T-cell precursor acute lymphoblastic leukaemia. Nature. 2012; 481(7380):157-63.

28. Guglielmelli P, Biamonte F, Score J, et al. EZH2 mutational status predicts poor survival in myelofibrosis. Blood. 2011;118:5227-34.

29. Abdel-Wahab O, Pardanani A, Patel J, et al. Concomitant analysis of EZH2 and ASXL1 mutations in myelofibrosis, chronic myelomonocytic leukemia and blast-phase myeloproliferative neoplasms. Leukemia. 2011;25(7):1200-2.

30. Bejar R, Stevenson KE, Caughey BA, et al. Validation of a prognostic model and the impact of mutations in patients with lower-risk myelodysplastic syndromes. J Clin Oncol. 2012.

31. Karanikolas BD, Figueiredo ML, Wu L. Polycomb group protein enhancer of zeste 2 is an oncogene that promotes the neoplastic transformation of a benign prostatic epithelial cell line. Mol Cancer Res. 2009;7(9):1456-65.

32. Holland D, Hoppe-Seyler K, Schuller B, et al. Activation of the enhancer of zeste homologue 2 gene by the human papillomavirus E7 oncoprotein. Cancer Res. 2008;68(23):9964-72.

33. Ernst T, Chase AJ, Score J, et al. Inactivating mutations of the histone methyltransferase gene EZH2 in myeloid disorders. Nat Genet. 2010;42(8):722-6.

34. Herrera-Merchan A, Arranz L, Ligos JM, et al. Ectopic expression of the histone methyltransferase Ezh2 in haematopoietic stem cells causes myeloproliferative disease. Nat Commun. 2012;3:623.

35. Brecqueville M, Cervera N, Adélaïde J, Rey J, Carbuccia N, Chaffanet M, Mozziconacci MJ, Vey N, Birnbaum D, GelsiBoyer V, Murati A. Mutations and deletions of the SUZ12 Polycomb gene in myeloproliferative neoplasms. Blood Cancer J. 2011;1:e33.

36. Score J, Hidalgo-Curtis C, Jones AV, et al. Inactivation of Polycomb repressive complex 2 components in myeloproliferative and myelodysplastic/myeloproliferative neoplasms. Blood. 2011;119:1208-13.

37. Gaebler C, Stanzl-Tschegg S, Heinze G, et al. Fatigue strength of locking screws and prototypes used in small-diameter tibial nails: a biomechanical study. J Trauma. 1999;47(2):379-84.

38. Gelsi-Boyer V, Trouplin V, Adelaide J, et al. Mutations of Polycomb-associated gene ASXL1 in myelodysplastic syndromes and chronic myelomonocytic leukaemia. Br J Haematol. 2009;145(6):788-800.

39. Metzeler KH, Becker H, Maharry K, et al. ASXL1 mutations identify a high-risk subgroup of older patients with primary cytogenetically normal AML within the ELN "favorable" genetic category. Blood. 2011;118:6920-9. 
40. Thol F, Friesen I, Damm F, et al. Prognostic significance of ASXL1 mutations in patients with myelodysplastic syndromes. J Clin Oncol. 2011;29(18):2499-506.

41. Fisher CL, Pineault N, Brookes C, et al. Loss-of-function additional sex combs like 1 mutations disrupt hematopoiesis but do not cause severe myelodysplasia or leukemia. Blood. 2010;115(1):38-46.

42. Dey A, Seshasayee D, Noubade R, et al. Loss of the tumor suppressor BAP1 causes myeloid transformation. Science. 2012.

43. Scheuermann JC, de Ayala Alonso AG, Oktaba K, et al. Histone H2A deubiquitinase activity of the Polycomb repressive complex PR-DUB. Nature. 2010;465(7295):243-7.

44. Caligiuri MA, Strout MP, Lawrence D, et al. Rearrangement of ALL1 (MLL) in acute myeloid leukemia with normal cytogenetics. Cancer Res. 1998;58(1):55-9.

45. Dohner K, Tobis K, Ulrich R, et al. Prognostic significance of partial tandem duplications of the MLL gene in adult patients 16 to 60 years old with acute myeloid leukemia and normal cytogenetics: a study of the Acute Myeloid Leukemia Study Group Ulm. J Clin Oncol Off J Am Soc Clin Oncol. 2002;20(15):3254-61.

46. Bernt KM, Armstrong SA. A role for DOT1L in MLL-rearranged leukemias. Epigenomics. 2011;3(6):667-70.

47. Jo SY, Granowicz EM, Maillard I, et al. Requirement for Dot11 in murine postnatal hematopoiesis and leukemogenesis by MLL translocation. Blood. 2011;117(18):4759-68.

48. Guenther MG, Levine SS, Boyer LA, et al. A chromatin landmark and transcription initiation at most promoters in human cells. Cell. 2007;130(1):77-88.

49. Lachner M, O’Sullivan RJ, Jenuwein T. An epigenetic road map for histone lysine methylation. J Cell Sci. 2003;116(Pt 11):2117-24.

50. Okada Y, Feng Q, Lin Y, et al. hDOT1L links histone methylation to leukemogenesis. Cell. 2005;121(2):167-78.

51. Krivtsov AV, Armstrong SA. MLL translocations, histone modifications and leukaemia stem-cell development. Nat Rev Cancer. 2007;7(11):823-33.

52. Bernard OA, Mauchauffe M, Mecucci C, et al. A novel gene, AF-1p, fused to HRX in $\mathrm{t}(1 ; 11)(\mathrm{p} 32 ; \mathrm{q} 23)$, is not related to AF-4, AF-9 nor ENL. Oncogene. 1994;9(4):1039-45.

53. Megonigal MD, Cheung NK, Rappaport EF, et al. Detection of leukemia-associated MLL-GAS7 translocation early during chemotherapy with DNA topoisomerase II inhibitors. Proc Natl Acad Sci USA. 2000;97(6):2814-9.

54. So CW, Karsunky H, Passegue E, et al. MLL-GAS7 transforms multipotent hematopoietic progenitors and induces mixed lineage leukemias in mice. Cancer Cell. 2003;3(2):161-71.

55. So CW, Cleary ML. Common mechanism for oncogenic activation of MLL by forkhead family proteins. Blood. 2003;101(2):633-9.

56. So CW, Lin M, Ayton PM, et al. Dimerization contributes to oncogenic activation of MLL chimeras in acute leukemias. Cancer Cell. 2003;4(2):99-110.

57. Shilatifard A, Lane WS, Jackson KW, et al. An RNA polymerase II elongation factor encoded by the human ELL gene. Science. 1996;271(5257):1873-6.

58. Prasad R, Yano T, Sorio C, et al. Domains with transcriptional regulatory activity within the ALL1 and AF4 proteins involved in acute leukemia. Proc Natl Acad Sci USA. 1995;92(26): 12160-4

59. Slany RK, Lavau C, Cleary ML. The oncogenic capacity of HRX-ENL requires the transcriptional transactivation activity of ENL and the DNA binding motifs of HRX. Mol Cell Biol. 1998;18(1):122-9.

60. Caligiuri MA, Schichman SA, Strout MP, et al. Molecular rearrangement of the ALL-1 gene in acute myeloid leukemia without cytogenetic evidence of 11q23 chromosomal translocations. Cancer Res. 1994;54(2):370-3.
61. Dorrance AM, Liu S, Yuan W, et al. Mll partial tandem duplication induces aberrant Hox expression in vivo via specific epigenetic alterations. J Clin Invest. 2006;116(10):2707-16.

62. Ernst P, Wang J, Huang M, et al. MLL and CREB bind cooperatively to the nuclear coactivator CREB-binding protein. Mol Cell Biol. 2001;21(7):2249-58.

63. Daigle SR, Olhava EJ, Therkelsen CA, et al. Selective killing of mixed lineage leukemia cells by a potent small-molecule DOT1L inhibitor. Cancer Cell. 2011;20(1):53-65.

64. Yao Y, Chen P, Diao J, et al. Selective inhibitors of histone methyltransferase DOT1L: design, synthesis, and crystallographic studies. J Am Chem Soc. 2011;133(42):16746-9.

65. Milne TA, Kim J, Wang GG, et al. Multiple interactions recruit MLL1 and MLL1 fusion proteins to the HOXA9 locus in leukemogenesis. Mol Cell. 2010;38(6):853-63.

66. Muntean AG, Tan J, Sitwala K, et al. The PAF complex synergizes with MLL fusion proteins at HOX loci to promote leukemogenesis. Cancer Cell. 2010;17(6):609-21.

67. Smith E, Lin C, Shilatifard A. The super elongation complex (SEC) and MLL in development and disease. Genes Dev. 2011;25(7):661-72.

68. Delmore JE, Issa GC, Lemieux ME, et al. BET bromodomain inhibition as a therapeutic strategy to target c-Myc. Cell. 2011;146(6):904-17.

69. Filippakopoulos P, Qi J, Picaud S, et al. Selective inhibition of BET bromodomains. Nature. 2010;468(7327):1067-73.

70. Zuber J, Shi J, Wang E, et al. RNAi screen identifies Brd4 as a therapeutic target in acute myeloid leukaemia. Nature. 2011;478(7370):524-8.

71. Nicodeme E, Jeffrey KL, Schaefer U, et al. Suppression of inflammation by a synthetic histone mimic. Nature. 2010;468 (7327):1119-23.

72. Dawson MA, Prinjha RK, Dittmann A, et al. Inhibition of BET recruitment to chromatin as an effective treatment for MLL-fusion leukaemia. Nature. 2011;478(7370):529-33.

73. Lohr JG, Stojanov P, Lawrence MS, et al. Discovery and prioritization of somatic mutations in diffuse large B-cell lymphoma (DLBCL) by whole-exome sequencing. Proc Natl Acad Sci USA. 2012;109(10):3879-84.

74. Morin RD, Mendez-Lago M, Mungall AJ, et al. Frequent mutation of histone-modifying genes in non-Hodgkin lymphoma. Nature. 2011;476(7360):298-303.

75. Pasqualucci L, Trifonov V, Fabbri G, et al. Analysis of the coding genome of diffuse large B-cell lymphoma. Nat Genet. 2011;43(9):830-7.

76. Ng SB, Bigham AW, Buckingham KJ, et al. Exome sequencing identifies MLL2 mutations as a cause of Kabuki syndrome. Nat Genet. 2010;42(9):790-3.

77. Glaser S, Lubitz S, Loveland KL, et al. The histone 3 lysine 4 methyltransferase, M112, is only required briefly in development and spermatogenesis. Epigenetics Chromatin. 2009;2(1):5.

78. Glaser S, Schaft J, Lubitz S, et al. Multiple epigenetic maintenance factors implicated by the loss of Mll2 in mouse development. Development. 2006;133(8):1423-32.

79. Bedford DC, Brindle PK. Is histone acetylation the most important physiological function for $\mathrm{CBP}$ and p300? Aging (Albany NY). 2012;4(4):247-55.

80. Petrij F, Giles RH, Dauwerse HG, et al. Rubinstein-Taybi syndrome caused by mutations in the transcriptional co-activator CBP. Nature. 1995;376(6538):348-51.

81. Miller RW, Rubinstein JH. Tumors in Rubinstein-Taybi syndrome. Am J Med Genet. 1995;56(1):112-5.

82. Kung AL, Rebel VI, Bronson RT, et al. Gene dose-dependent control of hematopoiesis and hematologic tumor suppression by CBP. Genes Dev. 2000;14(3):272-7. 
83. Xu W, Fukuyama T, Ney PA, et al. Global transcriptional coactivators CREB-binding protein and p300 are highly essential collectively but not individually in peripheral B cells. Blood. 2006;107(11):4407-16.

84. Rozman M, Camos M, Colomer D, et al. Type I MOZ/CBP (MYST3/CREBBP) is the most common chimeric transcript in acute myeloid leukemia with $\mathrm{t}(8 ; 16)(\mathrm{p} 11 ; \mathrm{p} 13)$ translocation. Genes Chromosomes Cancer. 2004;40(2):140-5.

85. Lai JL, Zandecki M, Fenaux P, et al. Acute monocytic leukemia with $(8 ; 22)(\mathrm{p} 11 ; \mathrm{q} 13)$ translocation. Involvement of $8 \mathrm{p} 11$ as in classical t(8;16)(p11;p13). Cancer Genet Cytogenet. 1992;60(2): $180-2$.

86. Huntly BJ, Shigematsu H, Deguchi K, et al. MOZ-TIF2, but not $\mathrm{BCR}-\mathrm{ABL}$, confers properties of leukemic stem cells to committed murine hematopoietic progenitors. Cancer Cell. 2004; 6(6):587-96.

87. Okano M, Xie S, Li E. Cloning and characterization of a family of novel mammalian DNA (cytosine-5) methyltransferases. Nat Genet. 1998;19(3):219-20.

88. Attwood JT, Yung RL, Richardson BC. DNA methylation and the regulation of gene transcription. Cell Mol Life Sci. 2002;59(2):241-57.

89. Ley TJ, Ding L, Walter MJ, et al. DNMT3A mutations in acute myeloid leukemia. N Engl J Med. 2010;363(25):2424-33.

90. Yamashita Y, Yuan J, Suetake I, et al. Array-based genomic resequencing of human leukemia. Oncogene. 2010;29(25): 3723-31.

91. Yan XJ, Xu J, Gu ZH, et al. Exome sequencing identifies somatic mutations of DNA methyltransferase gene DNMT3A in acute monocytic leukemia. Nat Genet. 2011;43(4):309-15.

92. Holz-Schietinger C, Matje DM, Reich NO. Mutations in DNA methyltransferase (DNMT3A) observed in acute myeloid leukemia patients disrupt processive methylation. J Biol Chem. 2012;287:30941-51.

93. Challen GA, Sun D, Jeong M, et al. Dnmt3a is essential for hematopoietic stem cell differentiation. Nat Genet. 2011;44: 23-31.

94. Delhommeau F, Dupont S, Della Valle V, et al. Mutation in TET2 in myeloid cancers. N Engl J Med. 2009;360(22): 2289-301.

95. Abdel-Wahab O, Mullally A, Hedvat C, et al. Genetic characterization of TET1, TET2, and TET3 alterations in myeloid malignancies. Blood. 2009;114(1):144-7.

96. Tahiliani M, Koh KP, Shen Y, et al. Conversion of 5-methylcytosine to 5-hydroxymethylcytosine in mammalian DNA by MLL partner TET1. Science. 2009;324(5929):930-5.

97. Figueroa ME, Abdel-Wahab O, Lu C, et al. Leukemic IDH1 and IDH2 mutations result in a hypermethylation phenotype, disrupt TET2 function, and impair hematopoietic differentiation. Cancer Cell. 2010;18(6):553-67.

98. Cimmino L, Abdel-Wahab O, Levine RL, et al. TET family proteins and their role in stem cell differentiation and transformation. Cell Stem Cell. 2011;9(3):193-204.

99. Shih AH, Abdel-Wahab O, Patel JP, et al. The role of mutations in epigenetic regulators in myeloid malignancies. Nat Rev Cancer. 2012;12(9):599-612.

100. Moran-Crusio K, Reavie L, Shih A, et al. Tet2 loss leads to increased hematopoietic stem cell self-renewal and myeloid transformation. Cancer Cell. 2011;20(1):11-24.

101. Quivoron C, Couronne L, Della Valle V, et al. TET2 inactivation results in pleiotropic hematopoietic abnormalities in mouse and is a recurrent event during human lymphomagenesis. Cancer Cell. 2011;20(1):25-38.

102. Ko M, Bandukwala HS, An J, et al. Ten-eleven-translocation 2 (TET2) negatively regulates homeostasis and differentiation of hematopoietic stem cells in mice. Proc Natl Acad Sci USA. 2011;108(35):14566-71.

103. Li Z, Cai X, Cai C, et al. Deletion of Tet2 in mice leads to dysregulated hematopoietic stem cells and subsequent development of myeloid malignancies. Blood. 2011;118:4509-18.

104. Busque L, Patel JP, Figueroa ME, et al. Recurrent somatic TET2 mutations in normal elderly individuals with clonal hematopoiesis. Nat Genet. 2012 (in press).

105. Jan M, Snyder TM, Corces-Zimmerman MR, et al. Clonal evolution of preleukemic hematopoietic stem cells precedes human acute myeloid leukemia. Sci Transl Med. 2012;4(149): 149ra118.

106. Mardis ER, Ding L, Dooling DJ, et al. Recurring mutations found by sequencing an acute myeloid leukemia genome. N Engl J Med. 2009;361(11):1058-66.

107. Tefferi A, Lasho TL, Abdel-Wahab O, et al. IDH1 and IDH2 mutation studies in 1473 patients with chronic-, fibrotic- or blast-phase essential thrombocythemia, polycythemia vera or myelofibrosis. Leukemia. 2010;24(7):1302-9.

108. Ward PS, Patel J, Wise DR, et al. The common feature of leukemia-associated IDH1 and IDH2 mutations is a neomorphic enzyme activity converting alpha-ketoglutarate to 2-hydroxyglutarate. Cancer Cell. 2010;17(3):225-34.

109. Dang L, White DW, Gross S, et al. Cancer-associated IDH1 mutations produce 2-hydroxyglutarate. Nature. 2009;462(7274):739-44.

110. Metzeler KH, Maharry K, Radmacher MD, et al. TET2 mutations improve the new European LeukemiaNet risk classification of acute myeloid leukemia: a Cancer and Leukemia Group B study. J Clin Oncol. 2011;29(10):1373-81.

111. Gaidzik VI, Paschka P, Spath D, et al. TET2 mutations in acute myeloid leukemia (AML): results from a comprehensive genetic and clinical analysis of the AML study group. J Clin Oncol. 2012;30(12):1350-7.

112. Xu W, Yang H, Liu Y, et al. Oncometabolite 2-hydroxyglutarate is a competitive inhibitor of alpha-ketoglutarate-dependent dioxygenases. Cancer Cell. 2011;19(1):17-30.

113. Sasaki M, Knobbe CB, Munger JC, et al. IDH1(R132H) mutation increases murine haematopoietic progenitors and alters epigenetics. Nature. 2012;488(7413):656-9.

114. Cairns RA, Iqbal J, Lemonnier F, et al. IDH2 mutations are frequent in angioimmunoblastic T-cell lymphoma. Blood. 2012;119(8):1901-3.

115. Lemonnier F, Couronne L, Parrens M, et al. Recurrent TET2 mutations in peripheral T-cell lymphomas correlate with TFHlike features and adverse clinical parameters. Blood. 2012;120(7):1466-9.

116. Couronne L, Bastard C, Bernard OA. TET2 and DNMT3A mutations in human T-cell lymphoma. $\mathrm{N}$ Engl $\mathrm{J}$ Med. 2012;366(1):95-6.

117. Wang Y, Wysocka J, Sayegh J, et al. Human PAD4 regulates histone arginine methylation levels via demethylimination. Science. 2004;306(5694):279-83.

118. Shi Y, Lan F, Matson C, et al. Histone demethylation mediated by the nuclear amine oxidase homolog LSD1. Cell. 2004;119(7): 941-53.

119. Klose RJ, Yamane K, Bae Y, et al. The transcriptional repressor JHDM3A demethylates trimethyl histone $\mathrm{H} 3$ lysine 9 and lysine 36. Nature. 2006;442(7100):312-6.

120. Koivunen P, Lee S, Duncan CG, et al. Transformation by the (R)-enantiomer of 2-hydroxyglutarate linked to EGLN activation. Nature. 2012;483:484-8.

121. Losman J-A, Lee S, Koivunen P, Looper RE, Kaelin, WG. Enantiomer-specific transformation by $2 \mathrm{HG}$ is linked to opposing effects on $\alpha$-ketoglutarate-dependent dioxygenases (Abstract LBA-4). Blood. 2011;118. 